\title{
Highlighting Cross-cultural Differences as Rhetorical Strategies in Tourism Marketing for Eurasian Countries
}

\author{
Asst. Prof. Dr. Ayca Oralkan (Beykent University, Turkey)
}

\begin{abstract}
Today, tourism represents a large part of the global economy. Tourism, which has become a widespread activity of the modern world, has generated a diversified marketing sector with motivations such as experiencing different natural conditions and different cultures. In addition to its contribution to regional development, the marketing of cultural tourism promotes multidimensional cultural characteristics that have a positive impact on the welfare of society. Quality of life as an understanding of life satisfaction is increased by the standards offered by tourism. In this context, tourism marketing strategies designed according to intercultural differences provide mutual benefits. The aim of this paper is to highlight possible rhetorical approaches to the attractiveness of cultural diversity that accompany the welfare effect of cultural tourism.
\end{abstract}

\section{Introduction}

In the 21 st century, tourism is representing a large chunk of the global economy as a mechanism for generating income and employment. While the modern world's life strategy has transformed tourism into a common spare time activity, involuntary retreat from nature and social life has created a diverse range of tourism demand. According to UNWTO (World Tourism Organization) data, the number of international tourists around the world was around 1.4 billion in 2018. In line with this global demand, cultural tourism is a multidimensional economic sector that makes a significant contribution to the economy of Eurasia countries. While cultural elements and activities provide an important motivation for travel, the process itself is involved in shaping the cultural structure (Richards, 2018, p. 12). In cultural tourism categorization, the experience of cultural attraction in touristic travel is the primary objective; for instance, a museum visit is decided before arriving at the destination (Hughes, 2002, p. 170). Although the concept of culture can be defined in many different ways, it ultimately represents the common life strategy and common values of the majority of its members. A possible social contact between individuals from different cultures can lead to the development of positive attitudes through mutual understanding. On the other hand, the contact between individuals from different cultures can generate negative attitudes through stereotypes, which can eventually lead to loss of sense of security (Reisinger, 1998 p. 82). Under such circumstances, tourist-host interaction is only disappointing rather than satisfaction. Therefore, it is necessary for tourism centers to highlight a tolerant approach, which is based on understanding and appreciation to ensure harmony, as well as intercultural differences, which are the elements of attraction.

Urban culture and heritage assets, such as museums, art galleries, historic centers, squares, theaters, and architecture, offer a wide range of cultural tourism opportunities. In this conjuncture, there is increasing competition for cultural tourism among the well-known destinations of countries across the globe. It is crucial for tourism marketing strategies to highlight cultural attractions and favorable cross-cultural differences to generate interest among tourist candidates. Past values tend to be nostalgic and regarding rhetorical analysis, such engagements are also very effective in tourism advertising. In addition to its contribution to regional development, marketing of cultural tourism promotes multidimensional cultural characteristics, which leads to positive effects on society's wellbeing. Quality of life as an understanding of life satisfaction has a tendency to get increased by the standards offered by tourism. In order to achieve sustainable tourism, it is necessary to meet the short and longterm standards of quality-living requirements of the local population, which is part of the tourism resource due to the nature of this interaction (Andereck et al., 2007, p. 484). For sustainable tourism, there is a clear definition as, "Tourism that takes full account of its current and future economic, social and environmental impacts, addressing the needs of visitors, the industry, the environment, and host communities" (UNWTO, 2005). In many countries around the world, investing in infrastructure and promotion for tourism development is state policy (Nowak, 2003, p: 4). In this context, the tourism marketing strategies of national tourism administrations and ministries of tourism, which are designed in accordance with cross-cultural differences lead a mutually beneficial path.

\section{Background}

Cultural tourism is a type of tourism activity where the main motivation of the visitors is to experience the cultural elements of a tourism destination and to consume the related products. Culture and tourism, by their nature, are interactively intertwined, and in view of the distinct link between culture and tourism, cultural tourism has begun to be defined as a particular type of consumption (Richards, 2018; p. 01). As income and consumption continued to increase in the mid-twentieth century, international travel and culture consumption also increased, and eventually, by the end of the 20th century, with the prominence of the main destinations of international tourists, cultural tourism began to gain importance. The capacity in international and domestic travels has increased with the undeniable effect of cultural tourism, contributing to the interactive development of economy and culture 
(Richards, 2001). In the middle of the twentieth century, cultural tourism, which was accepted as an elite form of tourism, started to become more evident in the mass-market since the 1990s through the fruitful interaction based on mutual interest generated by the relatively increasing satisfaction of tourists and their contribution to local economies (Jovicic, 2016, p. 2). In the 21 st century, cultural tourism has become a deep-rooted phenomenon in many tourism regions, with a sense of orientation towards the mass market. World Tourism Organization (UNWTO), through its publicly announced statement as an agency of the United Nations, promotes responsible, sustainable and universally accessible tourism. Confirming the significance of cultural tourism among the general motives of visit, UNWTO report (2018) emphasizes that international tourism has progressed towards the field of cultural practice worldwide.

Cultural attractions are usually in the open-air category, and when that is the case, it is very difficult to find reliable information about the number of tourists visiting and their possible motivations on these visits. On the other hand, methods that allow tourists to be grouped according to their cultural motivations are very important for the efficiency of management in any cultural center (Gali-Espelt, 2012, p. 46). For example, as a popular component of cultural tourism, culinary tourism is a well-known motivation for tourists who travel to learn about food and beverages in a given destination (Benkhard, 2017, p.41). Another example of the main motivations for international touristic visits is music with growing demand. Music events that can offer a wide range of activities ranging from Mozart in Salzburg to opera festivals in Bayreuth can increase the attractiveness of tourism centers (Hjalager, 2009, p. 266). Food-based traditions, diversified in the local gastronomy category, provide another motivation for tourists in search of exotic experiences. Festivals are also multicolored tourist motivations and comprehensive planning is required to provide a unique experience for their desired impact (Fernandes, 2014, p. 289).

\section{Main Focus of the Paper}

Given the increasing importance of cultural elements in the marketing of tourism, this paper aims to identify the current and possible future rhetoric trends towards this broad topic. The research methodology involves theoretical evaluations of tourism marketing among cross-cultural differences. The purpose of this paper is to emphasize the possible rhetoric approaches towards the attraction of cultural diversity accompanying the welfare impact of cultural tourism. In addition, in accordance with rhetoric analysis, there is the evaluation of possible advantages of cross-cultural differences and the interactive contribution of the resident support for culture-based tourism. In this regard, this paper presents cross-cultural evaluations on how the quality of life of the people living in tourism centers is affected.

\section{Economic Aspects of Cultural Tourism}

The economic return of cultural tourism has long been evident; in fact, cultural heritage can be said to be better protected through supportive tourism policies and tourism revenues. Even though it cannot be exactly known how much the income from tourism is spent on preservation and improvement of the cultural heritage, even the provision of the minimum value requirements can provide significant advantages. Cultural tourism has a significant contribution to the expansion of potential customer base, diversification of touristic facilities, lengthening of stay of tourists and reduction of seasonality. For example, this seasonality constraint has an important place among the challenges facing Turkey tourism. The number of tourists visiting Turkey with the motivation of cultural tourism is not very high and focusing mostly on summer vacationers as the target audience is often defined as the main problem. In order to reduce the seasonal effect, Turkey needs to position itself with cultural assets and values, and therefore needs to be able to use its cultural resources efficiently and effectively (Okumus et al., 2012, p. 648).

Because of all these important economic advantages, governments are trying to obtain formal approvals for the historical and cultural values of favorite destinations from global organizations such as Cultural Organization (UNESCO) and World Heritage Sites (WHS) (Patuelli, 2016, p. 2). Historical towns and historical corners of city centers are the main components of cultural heritage for Eurasian countries. Most of these open-air exhibitions, which are the focus of tourists, take place as the heritage sites in the list of UNESCO.

In addition, in order to provide further development of tourism, it is possible to provide unique experiences by developing creative economic approaches and to contribute to making tourist regions more attractive. When the experiences in a tourism center are diversified, the satisfaction of tourists can be increased, and therefore, tourists can be expected to repeat the selection of the location. A positive destination experience is not only the emotional appreciation of past satisfaction but also a direct impact on destination loyalty. Despite the tendency to attract new tourists in tourism marketing strategies, the destination loyalty is considered to generate fruitful intentions of revisits and place recommendations (Correia, 2013, p. 238). In this context, highlighting cross-cultural differences and original cultural resources that can arouse interest among tourist candidates is advantageous in the competitive environment. While the residence requirement of the people in the heritage sites continues to be met, the authenticity of the region must be maintained in line with the expectations of the tourists. 
As an extreme cross-cultural tourism phenomenon, indigenous tourism refers to the destinations in which, the focus of direct interest is the culture of indigenous people itself. In such cases, there may be policies that support the utilization of indigenous culture in the provision of economic efficiency in tourism enterprises (Whitford et al., 2001, p. 176). However, this is usually the case for Aboriginal category or locals of exotic islands rather than Eurasian countries.

Creative tourism is another efficient tourism phenomenon with the potential of transforming tourism experience in destinations into an unforgettable experience by making them even more impressive. The combination of cultural tourism with creative tourism comprising social and physical enhancements has the potential to transform an ordinary town into an attractive tourist center. Creative tourism has various aspects like enhancing the tourism experience and developing new thematic tourism products. In this context, contributing to local economies, creative tourism appears to provide more active and longer-lasting experiences (Chang, 2014, p. 4).

\section{Managing Overcrowding in Tourism}

While tourism provides economic contributions to the region by generating various options like the job options, unplanned growth in the tourist attractions can result in over-tourism. While enhancing the standards of infrastructure and facilities, it is crucial to provide consistent dynamics for the sustainability of the sector. A successful tourism marketing has the power to turn unknown places into popular tourist attractions. However, excessive use of natural resources such as water, and insufficient waste-discharging methods can create short and long-term problems for the region. Besides, the crowd can cause routine actions of daily life and all kinds of social activities to become a source of stress because of the excessive number of people (Neuts \& Nijkamp, 2012, p. 2134). At this point, there is the inspiring limitation approach of the World Tourism Organization through the definition of carrying capacity as, "The maximum number of people that may visit a tourist destination at the same time, without causing destruction of the physical, economic, socio-cultural environment and an unacceptable decrease in the quality of visitors" (UNWTO, 2005). Besides, in the analysis of crowded perception, coping methods with possible negative effects should be taken into account. Tourism centers that comply with this limitation approach of the World Tourism Organization can maintain the general satisfaction with the help of appropriate crowd-management methods in the tourist-intensive centers (Popp, 2012, p. 52). The main source for the motivation of the tolerance on the negative side effects is the mutually beneficial nature of mass tourism. Destination safety is another vital component as the mutual benefits of cultural tourism. Disruption of destination trust can turn into an irreversible weakness over the perception of tourist candidates. Therefore, the perception of trust upon tourism centers and their countries should be clearly established. In particular, the locals in the locations where tourism has an economic contribution will be the protectors of security in order to prevent tourism from being interrupted.

\section{Rhetoric Approach for Cultural Tourism}

The rhetoric, which has been used for centuries, is obliged to ensure that the messages of tourism marketing, which has been shining with the socioeconomic contributions over the past few decades, reach the potential tourists effectively. The Rhetoric strategy, which is the persuasion method, has three main components as Logos for the information given in the name of logic, Ethos for the credibility, and finally Pathos for the emotional effect (Aristotle, 4th century BC). By benefiting from the advantages of social media in communication strategy, it is possible to promote tourism centers efficiently and to reveal their favorable differences. The main characteristics of social media, such as a high message rate on a global scale and high return on investment (ROI), are important reasons for preference. Moreover, the potential efficiency of these marketing strategies has increased even more with smartphones that boost the rate of user interaction on the Internet. However, it can be very difficult to draw attention due to the very high number of shares and over-intensive information flow. Therefore, the choice of communication methods that can attract attention and interest is as important as the content of the message to be delivered to the tourist candidates in the target audience. In this conjuncture, rhetoric strategies aim to make these messages more convincing to target groups and there are efficient platform options that social media provides in this regard.

\subsection{Logos for Rhetoric Approach}

Internet memes are not only entertaining tools but also communication tools that can contain persuasive texts (Huntigton, 2013, p. 3). A slogan is a very effective communication tool to spread the image of the destination as a brand positioning strategy, and in terms of the effectiveness of brand messages, how spreadable that content is decisive. A successful slogan can provide an advantage in the competitive environment by contributing to the formation of brand identity through a perceptual difference (Pike, 2005, p. 259). Tourism centers are aware of the impact of the memes that can spread in social media and this communication method is considered as an influential strategy in marketing. Social media enables tourism centers to interact directly with tourist candidates through various Internet platforms, and to monitor their assessments of experiences. While each network platform generates its own advantages, simplicity is a critical characteristic enhancing the chance of the content spread 
faster. For instance, a core destination message as a Twitter text gets spread easier, an attractive visual as Instagram photo becomes viral much easier and links of touristic web addresses involving more detailed information can more effectively be shared on Facebook. However, the general slogans that do not focus on certain destination characteristics or cultural experiences, such as "exploring the potential" or "There are many things to discover", may not provide the intended differentiation. When it is a case of the spread of information, more focused slogans are able to provide strategic contents as valuable building blocks for destination image. While it is beneficial to focus on the agencies in the promotion of destination in the countries where the travel agencies are preferred, it is strategically critical to developing web pages with comprehensive and compelling information for countries, where tourists travel more often through the researches on the internet. Besides, it is strategically critical that the positioning in tourism marketing should be developed in such a way as to address the possible needs of potential tourists by investigating the cultural tendencies in target countries. Even in the responses to the slogans and promotional images used, there may be differences, depending on the cultural tendencies of the target countries. For example, in advertisements that are focused on cultures dominated by longing for the sea, slogans and promotional images highlighting the seas and beaches would be advantageous.

\subsection{Ethos for Rhetoric Approach}

A critical point in an environment where exaggerated or even false information circulates in destination promotions is reliability. Trust itself is about meeting the promises. Basically, trust has a very important impact on how tourism-related information is perceived from the very beginning. In other words, tourist candidates need to have an adequate level of trust in the tourism center and information sources to be able to approach the promotional information positively. Consistency is very important for the long-term reputation of tourism centers. Regardless of the tourism centers, even the unpleasant news from the country of origin may have negative effects. The more strongly and permanently established trust, the more effective-responsive approaches that neutralize consumer perceptions against possible negative information. In this context, one of the best ways of securing trust is the delivery of messages about promoted destinations via popular social media accounts such as popular Instagram accounts or popular YouTube channels instead of advertising agencies.

For effective tourism marketing strategy, it would be appropriate to carry out market segmentation for the formation of target groups that would increase the efficiency of promotional messages. Presenting all the elements of cultural diversity to all potential tourists can lead to a decrease in effectiveness by causing excessive information intensity and complexity. Positioning options in the destination include global, local and foreign elements. When evaluated in the rhetorical perspective, the global values would contribute to an acceptable level of compliance, thus contributing significantly to the need for reliability in the Ethos component. Therefore, positioning with a hybrid approach can be an optimum strategy (Akaka \& Alden, 2010, p. 49). While the perception of harmony built with the highlight upon global values ensures reliability, highlighting cross-cultural differences can provide advantages in the competitive environment.

\subsection{Pathos for Rhetoric Approach}

Due to the high number of attraction centers of the countries, the presentations that can be effective in the destination decisions of tourists are vital for the marketing strategies in order to gain an advantage by enabling differentiation in the competitive environment. Although cultural differences provide a natural advantage, there may be some humanitarian characteristics or social values in the context of the expectations of tourists. In view of the selective perception, consumers pay attention to messages that already contain the features they are looking for. Emotional appeal is a crucial variable of rhetorical works (Huhmann, 2010, p.13). When the information is shared with an emotional attachment the information is more likely to be remembered. Destination personality is a crucial component of tourism marketing and directly related to emotional experiences at a particular tourism center. Analyzing the destination personality with a tourist perspective can provide an understanding of the emotional connection to a particular destination (Kim \& Stepchenkova, 2017, p. 416). Tourists who experience a perceptual harmony between that destination and their own self-image have a tendency to revisit that destination (Matzler et al., 2016, p. 516). With an effective rhetoric perspective, the development of destination personality can enable tourists to express themselves through specific social values and individual-based styles that reflect a particular lifestyle. Or, for tourists who are looking for a break in their stressful life, the intimate and peaceful characteristics can be very attractive. Aaker's well-known statement, "the set of human characteristics associated with a brand", refers to the tendency to associate brands with positive human characters as sincerity, competence, excitement, sophistication, and ruggedness (Aaker, 1997, p. 351). Highlighting a certain character such as sincerity or excitement in harmony with cultural values and national trends can increase the effectiveness of cultural marketing strategy. In addition, globally positioned locations can be preferred by tourists for their expectation of a social lifestyle enhancement or a desire to gain international status. In this context, in marketing strategies, if the differentiated social values in the touristic regions are properly highlighted, accommodation periods and repeated visits may increase in these attraction centers. 


\section{Conclusion}

The global contribution of communication technology nourishes intense demand for the exchange of goods, services, information and capital based on cultural tourism worldwide. In this regard, cultural tourism is potentially effective in terms of these contributions to the opportunities for sustainable socio-economic development in Eurasian countries regarding welfare elements. Studies on tourism motivation are focused on acquiring information about travel behavior and have been one of the main elements of tourism literature. Especially in recent years, examining the tourist behavior has gained high significance with the fact that tourism, which is a critical component of the global economy, has become a cross-cultural phenomenon. A successful positioning provides an effective differentiation through these cross-cultural differences in the audience perception, among competing destinations. Besides, there are critical advantages of cross-cultural differences and the interactive contribution of the resident support for culture-based tourism. Beyond the regional impact of tourist expenditures, marketing of cultural tourism amplifies the benefits of this interaction by emphasizing the cultural values among the prosperity of social life. A positive experience at the tourism center is not only an emotional assessment of past satisfaction but also a direct impact on destination loyalty. Therefore, it is advantageous in the competitive environment to highlight cross-cultural differences and unique cultural resources that may attract interest among tourist candidates. Advertising, which aims to shape a positive image of tourism destinations through these cultural differences, plays an important role in promotion. Ads that highlight places to see using attractive promotional materials motivate tourist candidates to travel to these destinations. Apart from such advertising, mouth-to-mouth communication, and social media platforms that provide interactive communication, contribute significantly to the formation and promotion of destination images. In any case, it is crucial for destination trust to exist in advance in order for tourist candidates to positively evaluate the message content. In this regard, awareness-oriented messages -like the prevention of water pollution- lead advertisements to be positively perceived. However, effective destination management comprises long-run tourism planning and in order to gain the long-run trust, the consistency in the content of the messages is crucial. The halo effect generated by a strong destination trust can eliminate the hesitations of tourist candidates during the region selection and may even make the possible inconveniences that occur during their travels invisible.

\section{References}

- $\quad$ Aaker, J. L. (1997). Dimensions of Brand Personality. Journal of Marketing Research, 34(3), 347-356.

- Akaka, M. A., \& Alden, D. L. (2010). Global Brand Positioning and Perceptions: International Advertising and Global Consumer Culture. International Journal of Advertising, 29(1), 37-56. http://Doi.Org/10.2501/S0265048709201026

- $\quad$ Andereck, K. L., Valentine, K. M., Vogt, C. A., \& Knopf, R. C. (2007). A Cross-Cultural Analysis of Tourism and Quality of Life Perceptions. Journal of Sustainable Tourism, 15(5), 483-502. http://doi.Org/10.2167/Jost612.0

- Benkhard, B., \& Halmai, M. (2017). Mouthful Hungary - Overview of Hungarian Cuisine and Culinary Tourism. Geography and Tourism, 5(1), 41-54. http://doi.org/10.5281/zenodo.83449

- Chang, L. L., Backman, K. F., \& Huang, Y. C. (2014). Creative Tourism: A Preliminary Examination of Creative Tourists' Motivation, Experience, Perceived Value and Revisit Intention. International Journal of Culture, Tourism, and Hospitality Research, 8(4), 401-419. http://doi.org/10.1108/IJCTHR-04-2014-0032

- Correia, A., Kozak, M., \& Ferradeira, J. (2013). From Tourist Motivations to Tourist Satisfaction. International Journal of Culture, Tourism, and Hospitality Research, 7(4), 411-424. http://doi.org/10.1108/ijcthr-05-2012-0022

- Fernandes, C., \& Rachao, S. (2014). Reinventing Tourism at A Traditional Cultural Tourism Destination: A Case Study of Viana Do Castelo (Portugal). International Journal of Business and Globalisation, 12(3), 281296. http://doi.org/10.1504/ijbg.2014.060213

- Galí-Espelt, N. (2012). Identifying Cultural Tourism: A Theoretical Methodological Proposal. Journal of Heritage Tourism, 7(1), 45-58. https://doi.org/10.1080/1743873x.2011.632480

- Hjalager, A. M. (2009). Cultural Tourism Innovation Systems - The Roskilde Festival. Scandinavian Journal of Hospitality and Tourism, 9(2-3), 266-287. https://doi.org/10.1080/15022250903034406

- Hughes, H. L. (2002). Culture and Tourism: A Framework for Further Analysis. Managing Leisure, 7(3), 164-175. http://doi.org/10.1080/1360671022000013701

- Huhmann, B. A. (2010). A Model of The Cognitive and Emotional Processing of Rhetorical Works in Advertising. Go Figure: New Directions in Advertising Rhetoric, (September 2007), 133-175. https://doi.org/10.3386/w19846 
- Huntington, H. E. (2013). Subversive Memes: Internet Memes as A Form of Visual Rhetoric. Selected Papers of Internet Research, (2009), 2002-2005. Retrieved From http://spir.aoir.org/index.php/spir/article/view/785

- $\quad$ Kim, H., \& Stepchenkova, S. (2017). Understanding Destination Personality Through Visitors' Experience: A Cross-Cultural Perspective. Journal of Destination Marketing and Management, 6(4), 416-425. https://doi.org/10.1016/j.jdmm.2016.06.010

- $\quad$ Matzler, K., Strobl, A., Stokburger-Sauer, N., Bobovnicky, A., \& Bauer, F. (2016). Brand Personality and Culture: The Role of Cultural Differences on The Impact of Brand Personality Perceptions on Tourists' Visit Intentions. Tourism Management, 52, 507-520. https://doi.org/10.1016/j.tourman.2015.07.017

- $\quad$ Neuts, B., \& Nijkamp, P. (2012). Tourist Crowding Perception and Acceptability in Cities. Annals of Tourism Research, 39(4), 2133-2153. https://doi.org/10.1016/j.annals.2012.07.016

- Jovicic, D. (2016). Cultural Tourism in The Context of Relations Between Mass and Alternative Tourism. Current Issues in Tourism, 19(6), 605-612. https://doi.org/10.1080/13683500.2014.932759

- $\quad$ Nowak, J. J., Sahli, M., \& Sgro, P. M. (2003). Tourism, Trade and Domestic Welfare. Pacific Economic Review, 8(3), 245-258. http://doi.org/10.1111/j.1468-0106.2003.00225.x

- $\quad$ OECD Tourism Trends And Policies 2018. (2018). Paris: OECD Publishing. Retrieved April 4, 2019, from https://doi.org/10.1787/tour-2018-en

- $\quad$ Okumus, F., Avci, U., Kilic, I., \& Walls, A. R. (2012). Cultural Tourism in Turkey: A Missed Opportunity. Journal of Hospitality Marketing and Management, 21(6), 638-658. https://doi.org/10.1080/19368623.2012.627231

- $\quad$ Patuelli, R., Mussoni, M., \& Candela, G. (2016). The Effects of World Heritage Sites on Domestic Tourism: A Spatial Interaction Model for Italy. Advances in Spatial Science, (9783319301945), 281-315. https://doi.org/10.1007/978-3-319-30196-9_13

- Pike, S. (2005). Tourism Destination Branding Complexity. Journal of Product and Brand Management, 14(4), 258-259. https://doi.org/10.1108/10610420510609267

- Popp, M. (2012). Positive and Negative Urban Tourist Crowding: Florence, Italy. Tourism Geographies, 14(1), 50-72. https://doi.org/10.1080/14616688.2011.597421

- $\quad$ Reisinger, Y., \& Turner, L. (1998). Cross-Cultural Differences in Tourism: A Strategy for Tourism Marketers. Journal of Travel \& Tourism Marketing, 7(4), 79-106. http://doi.org/10.1300/j073v07n04

- Richards, G. (2014). Creativity and Tourism in The City. Current Issues in Tourism, 17(2), 119-144. https://doi.org/10.1080/13683500.2013.783794

- Richards, G. (2018). Cultural Tourism: A Review of Recent Research and Trends. Journal of Hospitality and Tourism Management, 36, 12-21. http://doi.org/10.1016/j.jhtm.2018.03.005

- $\quad$ UNEP, WTO, Tourism More Sustainable A Guide for Policy Makers Making (2005). Retrieved April 4, 2019, from http://sdt.unwto.org/content/about-us-5

- Whitford, M., Bell, B., \& Watkins, M. (2001). Indigenous Tourism Policy in Australia: 25 Years of Rhetoric and Economic Rationalism. Current Issues in Tourism, 4(2-4), 151-181. https://Doi.Org/10.1080/13683500108667886 